53 patients were included in control group (Group 2). The Lequesne Index was used to determine the severity of the disease.

Results All patients in group 1 and 31 patients in group 2 had knee pain and the mean duration of pain was $51.6+77.5$ months in group 1 and 23.4+46.5 months in group 2. The mean Body Mass Index (BMI) was $31.7+5.0$ in group 1 and $36.7+4.0$ in group 2. According to the results of scintigraphic evaluation, healthy controls were separated into two groups. In group $2 \mathrm{~A}$ patients who had an increase in uptake at least one joint and in group 2B patients who had no uptake. The mean MSS was 4.2 +1.4 in group 1 and $3.3+1.6$ in group $2 \mathrm{~A}$. Also the mean MRS of the patients in group 1 were $2.9+0.9$ and $0.6+0.5,0.2+0.4$ in group $2 \mathrm{~A}$ and $2 \mathrm{~B}$ respectively. The mean score of the Lequesne Index was $8,9+3,6$ in group 1 patients. There was a positive correlation between age and MSS $(p<0,05)$ and BMI and MRS $(\mathrm{p}<0,05)$. Also there was a strong correlation between Lequesne OA Severity Index Score the age of the patients in group 1 but no correlation with the MSS. According to the clinical and/or radiological criteria sensitivity of bone scintigraphy was $98.2 \%$, specifity was $57.1 \%$, positive predictive value was $76 \%$ and negative predictive value was $96 \%$.

Conclusion Our results suggest that $99 \mathrm{~m}$ technetium scintigraphy is a better quantifying method in assessing the changes of OA especially in early cases.

\section{SAT0209 MRI EVALUATION OF CHONDRAL LESIONS IN KNEE OSTEOARTHRITIS: ARTHROSCOPIC CORRELATION}

${ }^{1} \mathrm{C}$ Acebes, ${ }^{2} \mathrm{~A}$ Robledo, ${ }^{3} \mathrm{~J}$ Granizo, ${ }^{1} \mathrm{G}$ Herrero-Beaumont. ${ }^{1}$ Rheumatology; ${ }^{2}$ Radiology; ${ }^{3}$ Epidemiology, Fundación Jiménez Díaz, Madrid, Spain

\subsection{6/annrheumdis-2001.706}

Background Arthroscopic exam evaluation (chondroscopy) of the articular cartilage is considered a relevant instrument of OA outcome for research purposes. Nevertheless availablity of other accurate but non-invasive methods for chondral evaluation in OA, such us MRI, should be desireble.

Objectives To evaluate the capacity of MRI to score chondropathy in knee OA compared with chondroscopy.

Methods 24 consecutive patients diagnosed of knee OA were referred for knee hyaline cartilage MR imaging of medial chondile and tibial plateau with a fat-suppressed spoiled gradientecho sequences (SPGR) before chondroscopy. MRI and chondroscopic cartilage lesions evaluated by two methods were registered in an scale diagram and total score chondropathy was calculated using a software programme (Autocad). Correlation was determined by Sperman's test for both evaluation $(\mathrm{p}<$ $0,05)$.

Results High and significant intraobserver correlation was observed for evaluation of medial chondile and tibial plateau by chondroscopy $r=0,806$ and $r=0,721$ and by MRI $r=0,805$ and $\mathrm{r}=0,680$ respectively. Correlation coefficient between chondroscopic and MRI score for chondile and tibia was $r=$ 0,781 and $r=0,531$ respectively.

Conclusion Fat-suppressed SPGR imaging seems to be a relevant tool for evaluation of cartilage lesions in OA of the knee showing a high correlation between both procedures. Both chondroscopy and MRI have a lower correlation for the detection of chondral lesions in tibial plateau than in femoral chondile.

Supp. by a grant of Health Research Funding (98/626).
SAT0210 BRAIN MAGNETIC RESONANCE IMAGING (MRI) AND PROTON MAGNETIC RESONANCE SPECTROSCOPY (1HMRS) IN SYSTEMIC LUPUS ERYTHEMATOSUS (SLE)

${ }^{1} \mathrm{M}$ Govoni, ${ }^{2} \mathrm{P}$ Colamussi, ${ }^{1} \mathrm{~N}$ Rizzo, ${ }^{1} \mathrm{D}$ Santilli, ${ }^{3} \mathrm{R}$ Ricci, ${ }^{1} \mathrm{~F}$ Trotta. ${ }^{1}$ Sez. Di Reumatologia; ${ }^{2}$ Ist. Di Medicina Nucleare, Università Di Ferrara, Ferrara; ${ }^{3}$ Sevizio Di Neuroradiologia, Ospedale Bellaria, Bologna, Italy

10.1136/annrheumdis-2001.707

\section{Background}

Objectives We evaluated the usefulness of $1 \mathrm{H}-\mathrm{MRS}$ in patients with SLE, with or without neurological involvement, in whom single photon emission computed tomography (SPECT) showed cerebral perfusion abnormalities in brain areas with no detectable changes at MRI.

Methods 9 female SLE patients, with a mean age of 28.7 years (range 14-46) and a mean duration of disease of 2.5 years, underwent cerebral blood flow (CBF) study with 99mTc-SPECT and brain MRI with 1H-MRS analysis. 4 patients complained of headache, 1 patient was being treated for partial epilepsy and 4 patients were asymptomatic and with a negative neurological examination. In brain areas shown to be hypoperfused by SPECT, peak levels of signals from brain metabolites $\mathrm{N}$-acetylaspartic acid (NAA), choline (CHO), and creatine (CRE) were measured on a total of 20 brain voxels (volume $=8 \mathrm{~cm}^{3}$ ) selected on transverse MR images. Values were expressed as $\mathrm{NAA} / \mathrm{CHO}, \mathrm{CHO} / \mathrm{CRE}$ and NAA/CRE ratios. Ratios measured in 9 hypoperfused brain areas were compared with those obtained in 11 normoperfused areas. MRI showed a normal appearance in all of the above brain areas. Statistical analysis was performed by means of classical t-test.

Results NAA/CHO ratio was decreased in 78\% of hypoperfused and in $18 \%$ of normoperfused brain areas $(1.70 \pm 0.15$ vs 2.55 $\pm 0.16 ; \mathrm{p}=0.0017)$. $\mathrm{CHO} / \mathrm{CRE}$ ratio was increased in $89 \%$ of hypoperfused and in $9 \%$ of normoperfused brain areas $(1.34 \pm$ 0.08 vs $0.80 \pm 0.05 ; \mathrm{p}<0.0001)$. No significant differences were detected in NAA/CRE ratios. The comparison of spectroscopic ratios measured both in hypoperfused and normoperfused areas in patients with neurological symptoms with those obtained in asymptomatic patients did not show any significant differences.

Conclusion In SLE patients, independently from the presence of overt clinical neurological involvement, $1 \mathrm{H}-\mathrm{MRS}$ is a valuable tool to detect neuronal biochemical changes in brain regions with reduced CBF at SPECT. Although the precise meaning of these abnormalities remains to be determined, their localization in areas with reduced CBF suggests that they could represent an early sign of neuronal injury in SLE patients even in the presence of a normal brain MRI appearance. If proven so, 1H-MRS could be considered a sensitive and accurate measure of neuronal dysfunction in SLE and this would demonstrate that the detection of reduced CBF by SPECT in areas with a normal MRI appearance is not to be regarded as a false positive result.

\section{SAT0211 INTEROBSERVER AGREEMENT OF ULTRASOUND EXAMINATION IN ASSESSMENT OF THE SMALL JOINTS OF THE HANDS AND FEET IN RHEUMATOID ARTHRITIS}

${ }^{1} \mathrm{M}$ Szkudlarek, ${ }^{2} \mathrm{M}$ Court-Payen, ${ }^{1} \mathrm{~S}$ Jacobsen, ${ }^{3} \mathrm{H}$ Thomsen, ${ }^{4} \mathrm{M}$ Ostergaard. ${ }^{1}$ Department of Rheumatology; ${ }^{2}$ Department of Ultrasound; ${ }^{3}$ Department of Radiology, Herlev Hospital, Copenhagen, Denmark; ${ }^{4}$ The Danish Research Center of Magnetic Resonance, Hvidovre Hospital, Hvidovre

10.1136/annrheumdis-2001.708 